\title{
Closing the Gender Gap in Ischemic Heart Diseases and Myocardial Infarction
}

\author{
Maria Cristina Meira Ferreira, ${ }^{\circledR}$ Mayara Viana de Oliveira, ${ }^{\circledR}$ Maria Sanali Moura Paiva, ${ }^{3}{ }^{\circledR}$ Viviana Lemke, $^{4}{ }^{\circledR}$ \\ Fernanda Mangione, ${ }^{5}$ Gláucia Maria Moraes de Oliveira ${ }^{6}$ \\ Instituto Nacional de Cardiologia,' Rio de Janeiro, RJ - Brazil \\ Universidade Federal do Maranhão, ${ }^{2}$ Imperatriz, MA - Brazil \\ Universidade Federal do Rio Grande do Norte, ${ }^{3}$ Natal, RN - Brazil \\ Cardiocare, ${ }^{4}$ Curitiba, PR-Brazil \\ Hospital Beneficência Portuguesa de São Paulo, ${ }^{5}$ São Paulo, SP - Brazil \\ Universidade Federal do Rio de Janeiro, ${ }^{6}$ Rio de Janeiro, $R J$ - Brazil
}

Cardiovascular diseases (CVD) remain the leading cause of morbidity and mortality in women worldwide. Especially for women, traditional risk factors fail to explain most cases, deaths, and disability-adjusted life years (DALYs) from CVD. Risk factors inherent to the female sex and psychosocial aspects play an essential role in the development of CVD in women. Efforts need to be made to narrow the gap in diagnosis and treatment among women, especially younger ones, among whom CVD prevalence is increasing worldwide. ${ }^{1}$

Ischemic heart disease (IHD) remains a major threat to public health, and the overall burden is increasing globally. The GBD 2019 Study estimated 126.5 (95\% UI, 118.6-134.7) million prevalent cases of IHD in 2019 globally. Agestandardized rates for DALYs, deaths, and prevalent cases declined from 1990 to 2019, probably due to population growth and aging. ${ }^{2}$ In addition, IHD was the leading cause of death and DALYs in Brazil in 2019 for both males (12.22\% of total death $-95 \%$ UI, $11.5 \%-12.77 \%$; annual percent change -0.022$)$ and females (12.03\% of total death - 95\% UI, $10.66 \%-12.88 \%$; annual percent change 0.07$)$. It is important to note that there has been an increase in the annual percent change in mortality from IHD in women in recent years (Figure 1). ${ }^{3}$

The GBD 2017 estimated 1736 (95\% UI, 1689-1779) DALYs lost per 100000 individuals due to IHD, with lower rates

\section{Keywords}

Cardiovascular Disease; Myocardial Ischemia; Myocardial Infarction; Mortality; Prevalence; DisabilityAdjusted Life Years (DALY). for females (1127; 95\% UI, 1084-1163) than for males (2153; 95\% UI, 2067-2216), in 2017 in Brazil. From 1990 to 2017, there was a decline in DALYs lost for both males $(-47 \%)$ and females $(-52 \%)$ in all Brazilian Federative Units (Figure 2). ${ }^{4}$

In addition, the GBD 2017 estimated 84 events of IHD per 100000 inhabitants in 2017 in Brazil. The age-standardized incidence was 104 per 100000 inhabitants for males and 58 per 100000 for females. ${ }^{4}$ The GBD 2017 estimated a prevalence of IHD in 2017 of 2229 (95\% UI, 2098-2372) and 1008 (95\% UI, 938-1081) per 100000 inhabitants for males and females, respectively. The IHD prevalence increased in both sexes from 1990 to 2017 (Figure 3). ${ }^{4}$

\section{Mortality due to myocardial infarction}

Myocardial infarction (MI) is the leading cause of death in Brazil nowadays. The MI mortality rate decreased between 1996 and 2019, in both sexes, especially among females, being more relevant in the state capitals than in the inner areas. ${ }^{4}$

According to the Brazilian Unified Health System (SUS) Department of Information Technology (DATASUS), there were 142982 hospital admissions for MI in 2018, with inhospital mortality of $11 \%$. In 2018, the DATASUS registered 10811 primary angioplasties for MI, with in-hospital mortality of $6.3 \%$ and a mean length of hospital stay of 5.1 days. In 2018, the total amount reimbursed for coronary

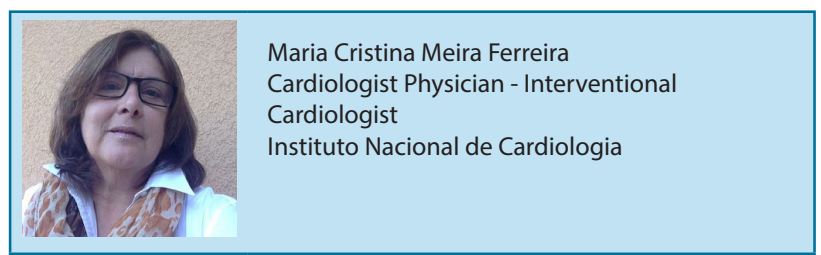

Mailing Address: Gláucia Maria Moraes de Oliveira

Universidade Federal do Rio de Janeiro - R. Prof. Rodolpho P. Rocco, 255 - 8. Andar - Sala 6, UFRJ. Postal Code: 21941-913, Cidade Universitária, RJ - Brazil E-mail: glauciam@cardiol.br, glauciamoraesoliveira@gmail.com 


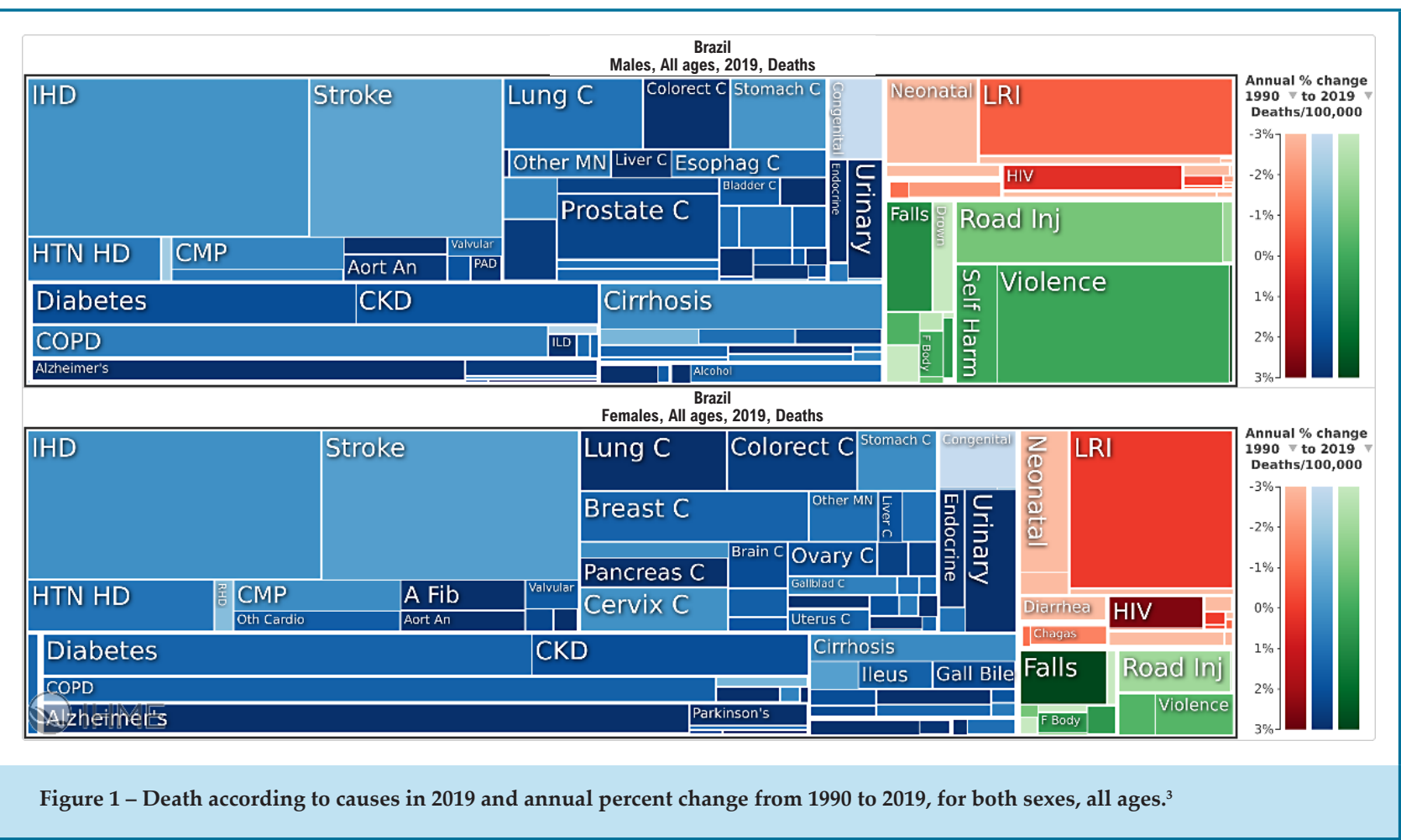

interventional procedures by the SUS was R $\$ 569314580$ (Int $\$ 280727$ 110), of which R 73429322 (13\%) (Int\$ 36202 821 ) were for primary angioplasties. ${ }^{4}$

In 2019 there were 56559 deaths from MI in men and 38991 in women, totaling 95550 deaths from MI. Most deaths occurred in the Southeast region, followed by the Northeast and South regions, with higher rates for males. The ratio between the gross rates of men and women in Brazil in 2019 was 1.49 (varying from 1.4 in the Southeast region to 1.8 in the Northeast region). These differences were less pronounced in older ages because of the female population aging. ${ }^{5}$

\section{Pathophysiology and clinical implications}

Myocardial infarction occurs mostly because of atherosclerotic plaque rupture with endothelial denudation, followed by sub-endothelial material exposure to bloodstream, triggering the coagulation process, with local formation of coronary thrombus and occlusion. This phenomenon of plaque rupture occurs in $76 \%$ of men and $55 \%$ of women. Considering the age of MI presentation, we can say that plaque rupture is rare in the premenopausal period. ${ }^{6,7}$ Several other pathophysiologies account for half of the other cases in women. ${ }^{6}$
The second most common cause of MI is plaque erosion, which is more prevalent in women and occurs both in post- and premenopause. Unlike rupture, it does not lead to endothelial denudation. Optical coherence tomography (OCT) has identified that plaque rupture occurs in thin capsule plaques with more abundant necrotic nuclei, typically called thin capsule fibroatheroma. In contrast, plaque erosion occurs in plaques with a larger fibrotic component and smaller necrotic core. Thrombus visualization by OCT in these two different pathophysiological situations has shown that the thrombi in plaque erosions are characteristically older and present for more days at the erosion site, leading to a more significant occurrence of thromboembolic phenomena. ${ }^{6,7}$

Whether differences between plaque rupture and plaque erosion require different therapies is still an open field of study. We know that primary angioplasty with stenting substantially modifies the clinical outcome of patients with MI. However, whether stents are equally effective in both pathophysiologies mentioned above is yet to be answered.

The diagnosis of MI in the absence of obstructive coronary disease or with vessel stenosis smaller than $50 \%$, known as MINOCA (myocardial infarction with nonobstructive coronary arteries), occurs five times more frequently in women, based on the VIRGO Study. ${ }^{8}$ In $1 / 3$ of the cases, MI presents as ST-elevation MI (STEMI) and 


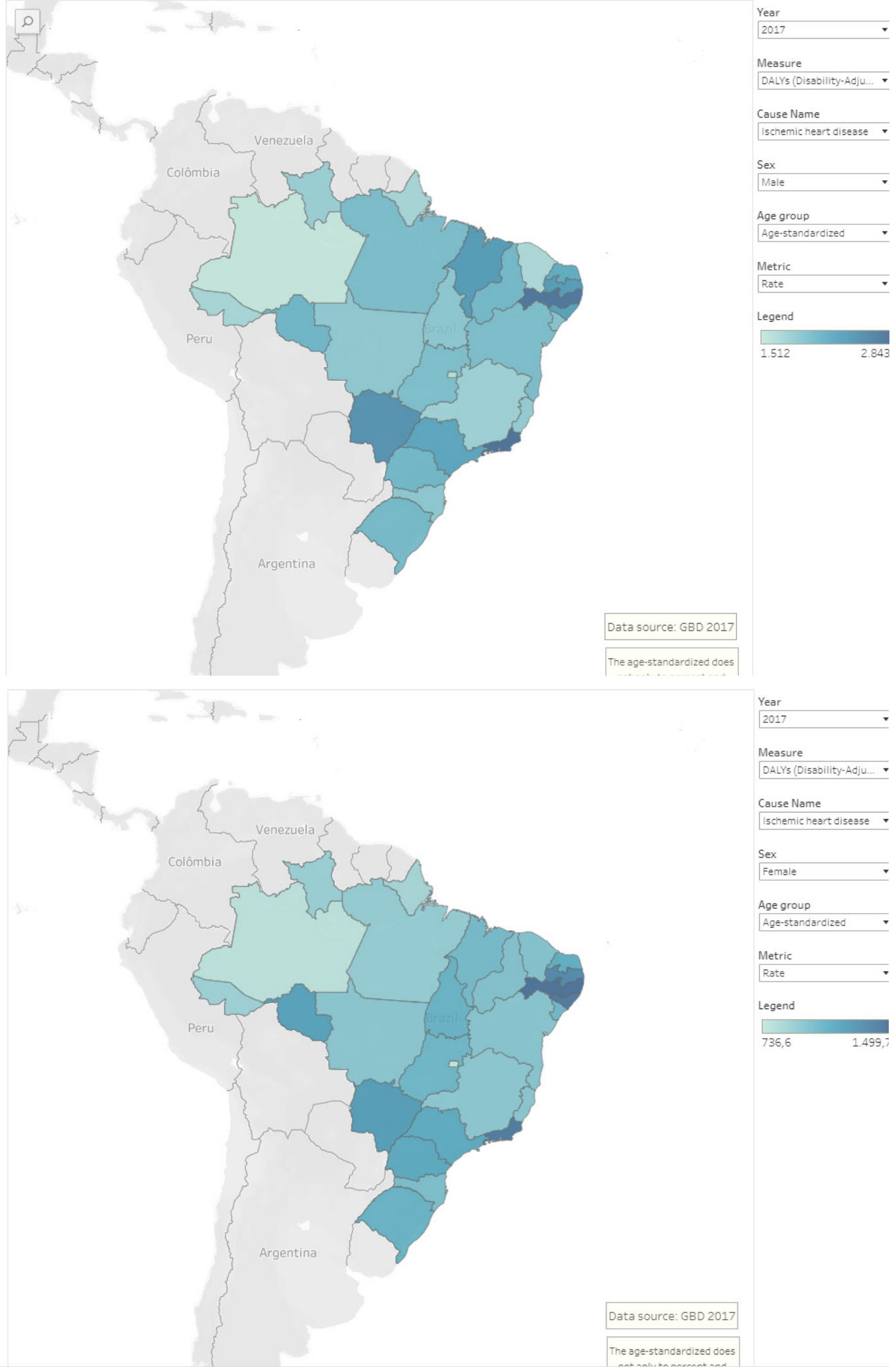

Figure 2 - Age-standardized DALYs, male (A) and female (B), per 100000 inhabitants, due to IHD in 2017 and annual percent change from 1990 to $2017 .^{4}$ 


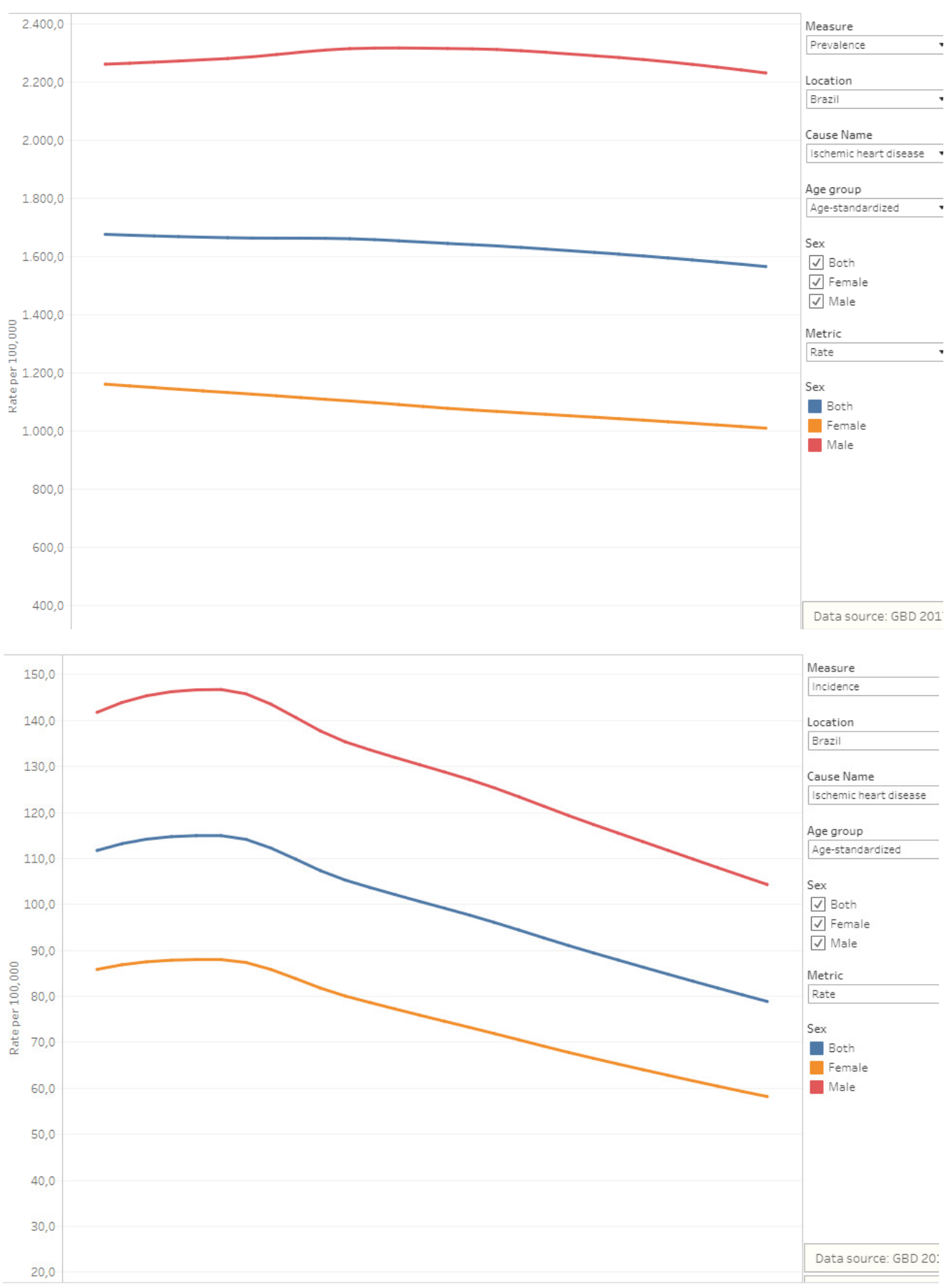

Figure 3 - Age-standardized prevalence (A) and incidence (B) of IHD per 100000 inhabitants in 2017 and annual percent change from 1990 to 2017, for both sexes. ${ }^{4}$

in 2/3 of the cases, as non-ST-elevation MI (NSTEMI). In addition, MINOCA occurs due to vasospasm of epicardial arteries, associated or not with microcirculation spasm and dysfunction. Vasospasm, as a cause of MI, is rare. It is controversial whether its prevalence is higher in women. However, the presence of coronary spasm in young women has worse prognosis than in older ones. Microcirculation dysfunction is widely accepted in the literature as being more frequent in women and closely related to diabetes mellitus. ${ }^{9,10}$ 
Two other causes of MINOCA that are more frequent in women are spontaneous coronary dissection and Takotsubo syndrome. Spontaneous dissection is directly related to young women with no risk factor for coronary atherosclerotic disease. ${ }^{9}$ It is diagnosed in $10 \%$ of women aged $<50$ years who present with MI, being associated with the peri- and postpartum period, use of oral contraceptives, and connective tissue diseases, mainly fibromyalgia, with a recurrence rate of around $17 \%$, according to Mayo Clinic studies. ${ }^{10,11}$ The Takotsubo syndrome is a cardiopathy related to intense physical or emotional stress, being more frequent in older women. ${ }^{9}$

The MI pathophysiologies, other than plaque rupture and erosion, are often underdiagnosed. They should always be in the minds of doctors, who, otherwise, will be at risk of misdiagnosing MI and consequently performing false prognoses when correlating the absence of obstructive coronary disease with an excellent long-term prognosis. Several studies in the literature have shown that patients with ischemia or MINOCA, especially those with microcirculatory dysfunction, have a less favorable prognosis. ${ }^{11-13}$

The correct diagnosis of MI directly influences the patient's prognosis, requiring an adequate perception of the referred symptoms to make the diagnosis as early as possible, allowing the implementation of a treatment capable of favorably changing clinical outcomes. Pain perception is multifactorial and influenced by physiological, anatomical, and psychosocial issues. Women present more frequently with atypical precordialgia and pain in the jaw, teeth, throat, back, abdomen and shoulder, in addition to nausea, vomiting, fatigue, and dyspnea. ${ }^{14}$

The population studied can influence the results. Medical reports on the initial presentation of established MI have shown that many women had atypical symptoms leading to an incorrect diagnosis. Because of that, women might have been excluded from the analysis of clinical trials. ${ }^{13,15}$

\section{Risk factors for ischemic heart disease and myocardial infarction}

The traditional risk factors for CVD are the same for women and men. However, the differences in the prevalence and impact of these factors vary between genders. Studies point out that women with MI are generally older and have more comorbidities, such as hypertension, dyslipidemia, diabetes, heart failure, and atrial fibrillation. Smoking and diabetes mellitus have a more substantial impact on women. Women $<65$ years of age with a maternal history of MI are four times more likely to have MI than men of the same age or older women. Young and middle-aged women who smoke have a $25 \%$ higher risk of fatal and non-fatal cardiovascular (CV) events. ${ }^{16}$

Women hospitalized with type 1 and type 2 MI have lower socioeconomic status, higher levels of psychosocial disorders, poorer physical/mental health, and lower quality of life than men. Depression, trauma, and stress are powerful predictors of $\mathrm{CV}$ risk in young and middle-aged women because of their continuous increase in economic participation and their search for educational achievement. ${ }^{16}$

Early menopause and postmenopause are associated with an adverse risk for CVD. Estrogen has an antiinflammatory effect and promotes low vascular resistance, protecting premenopause women. Estrogen reduction in menopause has many adverse effects on CV function and metabolism, including changes in body fat distribution, endothelial dysfunction, vascular inflammation, increased sympathetic tone, and increased insulin resistance that contributes to hypertension. However, although initially supported by extensive observational studies, randomized controlled trials have failed to show any $\mathrm{CV}$ benefit from menopausal hormone replacement therapy (HRT). They have even demonstrated an increase in MI in postmenopausal women. Thus, the use of HRT for primary and secondary prevention of CVD remains controversial and is currently not recommended. ${ }^{17}$

Iron deficiency is known to increase adverse CV outcomes in women and men. There is a hypothesis that changes in plasma iron levels and metabolism after menopause would negatively affect the CV system due to inflammatory cascade induction. ${ }^{18}$ Interestingly, a study has suggested that iron level changes might be an alternative mechanism responsible for the increased risk seen in postmenopausal women. However, the iron hypothesis remains controversial due to the lack of clinical trials to support this thesis. ${ }^{19}$

Pregnancy-related complications are associated with increased CV risk. A recent meta-analysis has concluded that the risk of IHD was higher in women with a history of preeclampsia, placental abruption, gestational hypertension, and diabetes. ${ }^{20}$ In addition, the development of gestational diabetes has increased the risk of IHD two to three times up to 25 years after delivery. ${ }^{21}$ Pimiparas during 
premature delivery ( $<37$ weeks of gestation) had a 1.5-time greater risk of IHD. ${ }^{22}$

These traditional and gender-related risk factors increase female susceptibility to MI and short-term adverse effects after MI. Female gender is a risk factor for bleeding after a percutaneous coronary intervention (PCI). This fact may have contributed to the non-predilection for drug-eluting stents in women. This risk may be even greater among patients at high risk for bleeding. Factors, such as older age and higher prevalence of comorbidities, confer a greater ischemic risk on women. They promote an underutilization of therapies directed to women in MI guidelines. ${ }^{23}$ In addition, women with STEMI have an increased risk of bleeding compared to men. Although the female sex may not directly contribute to the increased risk of major adverse cardiac events (MACE), it is associated with comorbidities that increase the risk of ischemic events in the long term. ${ }^{24}$

\section{Clinical and laboratory diagnosis}

The risk factors for CVD are similar for both sexes. However, the weight of the risk factors may be different. Data from the INTERHEART Study suggest that $96 \%$ of MI risk attributable to the female population occur due to the so-called "modifiable" factors, such as smoking, hypertension, diabetes, obesity, physical activity, alcohol consumption, lipids, and psychosocial factors. Ethnicity is a crucial factor for MI in the female sex because black women have a higher prevalence of MI than the others, including higher cardiac death rates. Asian and Indian women also have higher mortality rates, likely to be associated with higher CVD risk factors. ${ }^{25,6}$

The main symptom that leads to the diagnosis and should trigger treatment initiation in patients with suspected MI is acute chest discomfort, described as pain, pressure, tightness, and burning. Although most patients, including women, have a typical condition, women most often report atypical chest pain or associated symptoms, such as dyspnea, fatigue, sweating, and epigastric pain. ${ }^{6}$

The 12-lead electrocardiogram (ECG) should be performed within 10 minutes after the arrival of the patient with suspected MI to the emergency room, or even in a pre-hospital environment, especially in the search for ST-segment changes. ${ }^{25}$ Persistent ST-segment elevation lasting more than 20 minutes should trigger referral for immediate reperfusion by primary PCI or, if not available promptly, by fibrinolytic therapy. Patients with acute chest discomfort but without persistent ST-segment elevation may exhibit transient ST-segment elevation, persistent or transient ST-segment depression, T-wave inversion, flat T waves or T-wave pseudo-normalization; normal ECG is found in approximately $30 \%$ of those patients..$^{25}$

Measuring highly sensitive troponin is recommended for all MI patients. However, it is worth noting that many cardiac pathologies, in addition to MI, result in damage to myocardial cells and, therefore, elevations in cardiac troponin. Other biomarkers may be necessary in specific clinical settings when used in combination with the nonhighly sensitive troponin T or I. For example, CK-MB shows a faster decline after MI and may assist in the detection of early reinfarction. The initial troponin levels add prognostic information regarding short and long-term mortality to the clinical and ECG variables. In addition, serum creatinine and estimated glomerular filtration rate should be determined in all patients with STEMI because they affect the prognosis and are crucial elements of the GRACE risk score. A GRACE risk score $>140$ and dynamic changes in the ST segment recommend an early invasive approach (within 24 hours of admission). ${ }^{26,27}$

Several non-invasive testing techniques may be appropriate in detecting microvascular IHD in women. For high-risk NSTEMI patients, catheterization remains the standard reference approach. ${ }^{25,26}$

An analysis of 68730 patients enrolled in ten STEMI clinical trials has shown that women have higher rates of all-cause mortality and similar MACE rates. ${ }^{26}$ Women with MI should have equal access, immediate diagnosis, and treatments at the same quality and intensity as those offered to male patients. However, these women may receive a higher dose of antithrombotic medication than is appropriate to their weight or kidney function, or both. These may be responsible for the increased risk of inhospital bleeding complications related to these patients' vascular access. ${ }^{26,27}$

\section{Treatment}

Since the 1980s, mortality from MI in women has exceeded that in men. ${ }^{6}$ Some studies question the higher MI mortality in women because previous analyses referred to relative mortality, while the most recent trials use standard mortality. Some variables interfere in this MI-related mortality calculation and its associated factors that could disappear when adjusted. ${ }^{28,29}$

Women receive less aggressive drug therapy because they have more associated comorbidities, are older, underdiagnosed, and delay the initial presentation 
with lower reperfusion therapy use. After adjusted analysis, there would be no significant differences in mortality between the sexes, decreasing in the STEMI and disappearing or even favoring women in NSTEMI. ${ }^{29}$

Delay in women presenting to medical services to receive initial reperfusion therapy, whether due to thrombolytics or coronary angioplasty, is a challenge to be overcome. Women benefit more than men from primary angioplasty and have a worse prognosis than men when the initial treatment is fibrinolysis. ${ }^{30}$ Reports from the GUSTO (Global Utilization of Streptokinase and Tissue Plasminogen Activator for Occluded Coronary Arteries) Study show that women have more strokes, heart failure, shock, bleeding, recurrent angina, and infarction than men when undergoing thrombolysis. ${ }^{31}$

The study by Alabas et al. ${ }^{29}$ assessing mortality from MI in the SWEDEHEART Registry, has shown statistically significant differences between sexes in the application of different therapies. Women received a lesser percentage of reperfusion therapy by both fibrinolysis and angioplasty. The same happens with drug therapy, including aspirin, beta-blockers, statins, P2Y2 inhibitors, angiotensinconverting enzyme (ACE) inhibitors, and angiotensin receptor blockers. ${ }^{29}$ These data reinforce the need to intensify the population's and the health team's awareness of the different symptoms in this group to decrease the interval between symptom onset and therapy and improve treatment to achieve the same management percentages indicated in the guidelines for both sexes.

In cases of NSTEMI, early revascularization is also favorable. The elevation of the myocardial necrosis marker is essential for early intervention, which can be more challenging in women. In the study by Slagman et al., troponin has shown a lower positive predictive value in women (53.5\%; 95\% CI: 42.4-64.3) when compared to men $(60.8 \%$; $95 \%$ CI: $54.1-67.2)$ and a slightly higher negative predictive value for women than for men [97.1\% (95\% CI 96.0-97.9) vs. 96.3\% (95\% CI 95.2-97.2), respectively]. ${ }^{32}$

Women are at higher risk of bleeding when undergoing PCI. ${ }^{33}$ Females have a higher prevalence of risk factors calculated in the HAS-BLED (Hypertension, Abnormal renal and liver function, Stroke, Bleeding, Labile INR, Elderly, Drugs, or alcohol) score. Women have a higher incidence of atrial fibrillation during the acute event, requiring oral anticoagulation associated with dual antiplatelet therapy (DAPT) if submitted to intervention with coronary stent, which increases the bleeding risk. ${ }^{6}$
First-generation drug-eluting stents have shown high mortality in women; thus, some studies have preferred to use conventional stents in women. However, stateof-the-art stents and even stents dedicated to patients at high risk of bleeding are superior to previous ones in decreasing MACE in this group. ${ }^{34}$

We must not forget that MINOCA cases require adequate treatment, never inappropriately inferring that the absence of obstructive coronary disease means a better prognosis. Studies on the functional assessment of vascular reactivity and microcirculation dysfunction can identify MI causes and the need for individualized treatment. The CorMicA Trial refers to therapy with nitrates and calcium blockers in vasospasm and betablockers, statins, and ACE inhibitors in microcirculatory disorders. ${ }^{35}$ In spontaneous coronary dissections, conservative treatment is the first choice, unless hemodynamic instability is present. ${ }^{36}$

Invasive physiological assessment of myocardial infarction in women

The use of physiological assessment as a decision-making method for performing complete revascularization in $\mathrm{MI}$ has been supported by the DAMINI 3-PRIMULTI and ACUTE COMPARE trials. ${ }^{37,38}$ Both studies have used the fractional flow reserve (FFR) to assess the functional importance of non-culprit artery lesions. The DAMINI 3-PRIMULTI Trial has evaluated the culprit artery 48 hours after the acute event and primary angioplasty. The ACUTE COMPARE Trial has performed the functional evaluation in the same primary angioplasty procedure. Compared with the angioplasty of the culprit artery alone, both studies have shown decreased subsequent revascularizations when using the FFR, with no decrease in hard outcomes, such as death and infarction. The COMPLETE Trial, comparing complete angiography-guided revascularization versus target-lesion revascularization, has shown a reduction in death and MI in a 3-year follow-up. ${ }^{39}$

The FFR use in MI requires normal microcirculation to react with maximum hyperemia after vasodilator. ${ }^{40}$ Although the instantaneous wave-free ratio (iFR) does not dependent on the microcirculation and does not require a vasodilator, it has not been evaluated in the MI scenario. An FFR $<0.80$ suggests the need for revascularization, and an FFR $>0.80$ may be overestimated because of the inadequate response to microcirculation vasodilation in MI due to a decrease in 
the gradient between pre- and post-stenosis pressures. (Figure 4$)^{40}$

The impact of that analysis is more significant when MI occurs in women, because they have a higher prevalence of microcirculatory dysfunction. Women have been proven to have higher mean FFR than men. ${ }^{6,41} \mathrm{~A}$ recent study assessing the microcirculation situation in the non-culprit vessel during the acute event, even with small sampling and $80 \%$ being male, has found $93 \%$ of patients with some degree of dysfunction and only $34 \%$ of abnormal FFR. ${ }^{42}$

It is worth noting that plaque erosion occurs significantly more often in women in association of higher frequency of distal microembolization that mechanically impacts microcirculation. ${ }^{6}$ So far, there has been no certainty as to how long after MI normalization of the microcirculation occurs. Because it is often a mechanical phenomenon and not exclusively metabolic, the period required to return to normality may be much longer than a few days.

Thus, whenever the FFR $>0.80$ at any time during the acute or subacute phase of MI, the functional assessment of the microcirculation, using a specific index for that, would be ideal. The indices of functional assessment of the microcirculation, such as coronary flow reserve and hyperemic microcirculation ratio, are essential but little used in clinical practice because of their complexity. On the other hand, the index of microvascular resistance, performed by using thermodilution, is easy to use in catheterization laboratories, reproducible and reliable, being identified as a predictor of clinical outcomes in the CORMICA Trial. ${ }^{43,44}$

Considering the pathophysiology of MI in women, the research of vascular reactivity of both macro and micro coronary circulations can identify vasospastic phenomena as causing the acute event. The use of intravenous or intracoronary acetylcholine with evidence of significant spasm of coronary epicardial vessels guides us to diagnose macrovascular spasm. In contrast, the presence of angina symptoms and evidence of ischemia, in the absence of epicardial coronary vasospasm, lead us to the probable diagnosis of microvascular spasm. ${ }^{43}$

In conclusion, the use of invasive physiological assessment in women with MI should be carefully

\section{Coronary Circulation}

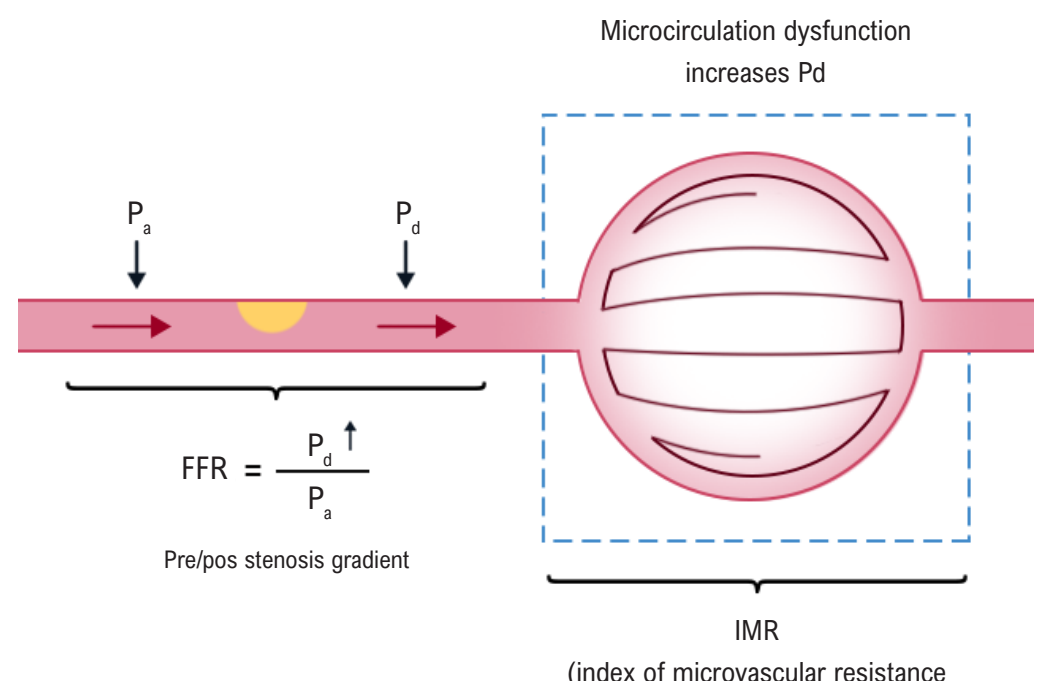

(index of microvascular resistance

Figure 4 - Representation of an epicardial vessel with stenosis (yellow) and microcirculation distal to the lesion. Fractional flow reserve (FFR) analysis assesses the difference between pre-stenosis pressure $(\mathrm{Pa}=$ aortic pressure) and post-stenosis pressure $(\mathrm{Pd}$ $=$ distal pressure). While FFR is an index to assess only lesions in epicardial vessels, the index of microvascular resistance (IMR) is only for microcirculatory assessment. In the presence of dysfunction of the microcirculation, the IMR increases. It can be easily seen that the microcirculatory dysfunction interferes in the velocity of blood flow distal to the epicardial lesion, increasing Pd. With this elevation in the numerator of the fraction ' $\mathrm{Pd} / \mathrm{Pa}$ ', FFR is overestimated. ${ }^{40}$ 
analyzed, never considering the investigation completed if FFR $>0.80$, requiring associated diagnostic tests.

\section{Percutaneous invasive treatment}

Women and young people are more likely to have normal coronary arteries or mild irregularities, diffuse disease, single-vessel disease, or other angiographic findings, such as coronary dissection, when facing MI. The CASS trial, comparing angiographic results in young men and women, has observed frequent normal coronary arteries in young women. ${ }^{45-50}$ Moreover, having MI symptoms with normal coronary arteries, about $20 \%$ of young women will have myocardial ischemia, probably due to microcirculation involvement. ${ }^{51-54}$

There is an established benefit for men using an early invasive strategy for NSTEMI and revascularization, if applicable. However, among women, this strategy has specific nuances. Contemporary meta-analysis has shown that, for men, the early invasive approach improves survival. However, for women, the benefit is more significant in the population with an elevation of troponin markers (OR 0.47, 95\% CI: 0.26-0.83). ${ }^{47}$ A subsequent meta-analysis involving 3000 women and 7000 men has corroborated that same concept, but it has not occurred in low-risk women with negative biomarkers. ${ }^{47}$

In general, even more recently, the routine of treating women less aggressively in the presence of STEMI has persisted. A recent review based on CRUSADE with approximately 36000 patients, $41 \%$ of whom were women, has found that this group was treated less aggressively than men. In a lower percentage, women underwent cardiac catheterization within 24 hours of admission (42\% x 49\% among men). Consequently, they had a lower percutaneous treatment rate simultaneously (44\% x 52\% for men). ${ }^{46}$

Data obtained from two major academic health systems in the United States between 2000 and 2016 demonstrated that a lower percentage of women under 50 years of age affected by MI were submitted to coronary revascularization $(82.1 \%$ against $92.6 \%$ among men, $\mathrm{p}<0.001){ }^{48}$

In STEMI, women undergoing primary angioplasty have a higher risk of in-hospital and late mortality, perhaps because they are older and have more comorbidities, which have also been found in the CADILLAC trial. At the end of 1 year after MI, women have significantly higher rates of mortality $(7.6 \times 3 \%$ among men), targetvessel revascularization $(16.7 \times 12.1 \%)$, and major adverse events $(23.9 \times 15.3$ for men $) .{ }^{49}$ These differences are due to their higher prevalence of risk factors, such as diabetes, hypertension, and kidney failure, their lower body surface area, and the use of drugs, such as anticoagulants, without adjustment to weight. ${ }^{49,50}$ However, after adjustments, the female gender was not a risk factor for mortality in the CADILLAC trial.

It is important to note that women have a higher ischemic risk and a higher risk of sex-related bleeding. Biological factors linked to the female gender may hinder DAPT, and they should be included in the bleeding scores. In addition, women are underrepresented in studies involving DAPT because of sex-related factors and cultural and socioeconomic characteristics. ${ }^{55}$ The higher risk of bleeding and the early cessation of DAPT, coupled with elevated ischemic risk in women, increase the worst results after PCI and hinder PCI performance. ${ }^{23.24,56}$

\section{Clinical implications}

This review highlights the sex and gender influences that exist for IHD and MI. Figures 5 and 6 summarize the main points.

Ischemic heart disease and heart failure with preserved ejection fraction due to IHD are significant contributors to heart disease mortality in women. Of note, systolic blood pressure and hypertension, smoking, and diabetes are associated with higher hazard ratios for MI in women than in men. ${ }^{56}$

In addition, a study has reported that women with MI treated by male emergency doctors have a higher mortality rate than those treated by female emergency doctors. The MI approach is more effective when female patients are treated by female doctors. ${ }^{57}$

In conclusion, sex influences disease pathophysiology, clinical presentation, response to treatment, clinicians' behavior, and how and when patients have access to health care. Precision medicine must consider sex and age at a high decision level to promote correct IHD and MI diagnosis, as well as treatment and gender equity in health care. ${ }^{56}$

\section{Author contributions}

Conception and design of the research: Ferreira MCMF, Oliveira MV, Oliveira GMM. Acquisition of data: Ferreira MCMF, Oliveira MV, Paiva MSM, Lemke V, Mangione F, Oliveira GMM. Analysis and interpretation 


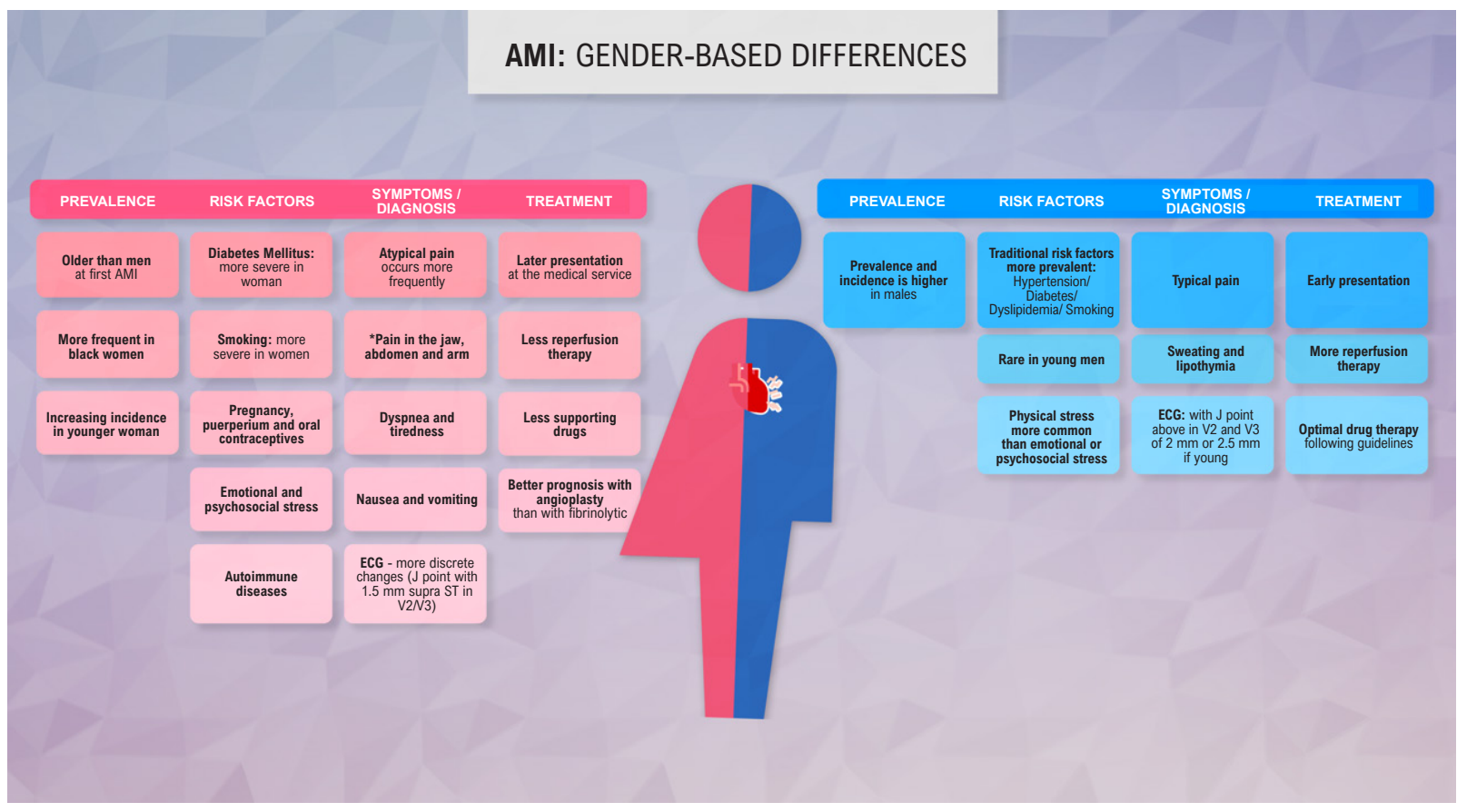

Figure 5 - Sex-based differences in prevalence, risk factors, symptoms, diagnosis, and treatment ${ }^{6,16,55}$ MI: myocardial infarction; ECG: electrocardiogram; FFR: fractional flow reserve.

\section{AMI: GENDER-BASED DIFFERENCES}

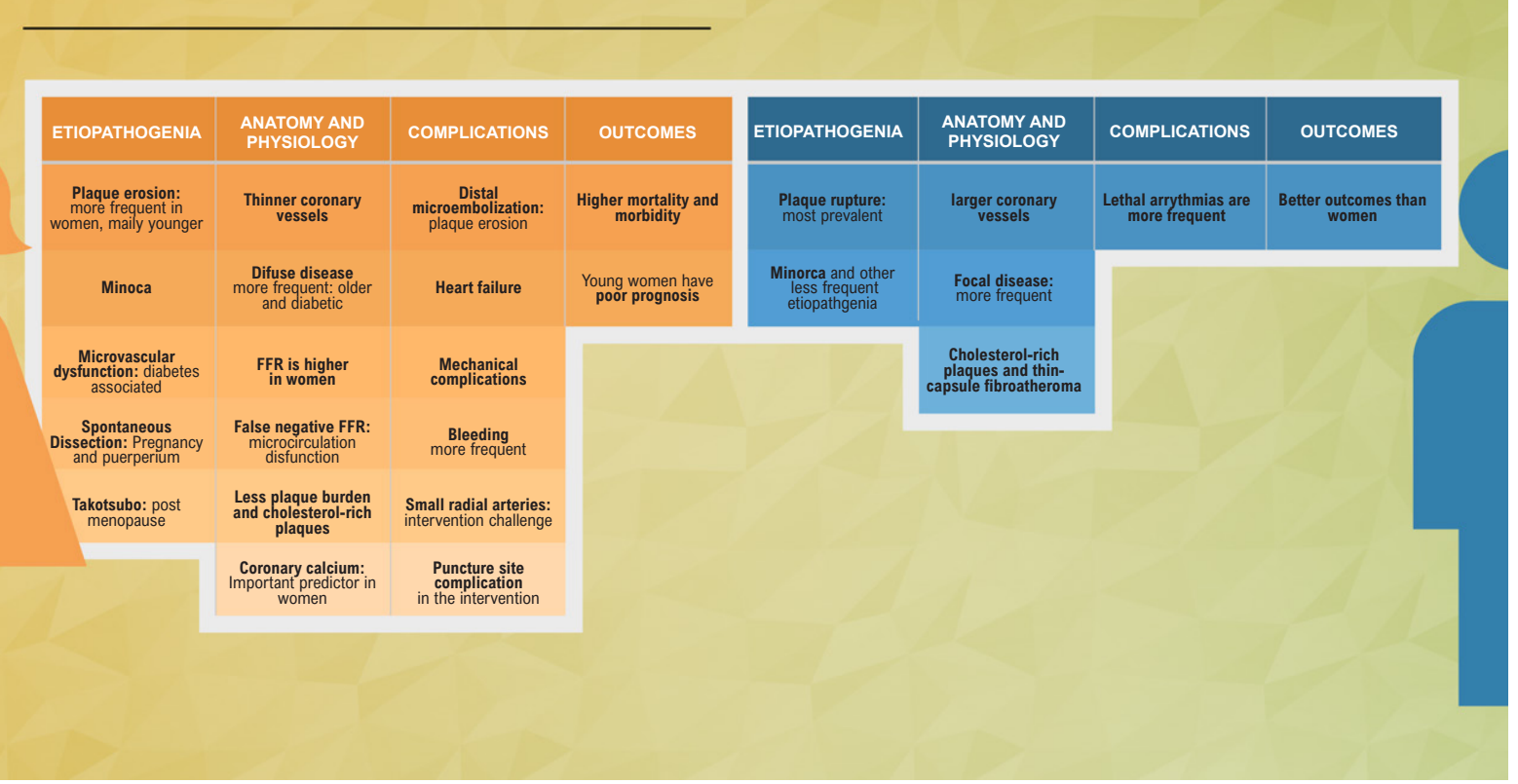

Figure 6 - Sex-based differences in etiopathogenesis, anatomy, physiology, complication, and outcomes. ${ }^{6,16}$ MI: myocardial infarction; MINOCA: myocardial infarction with nonobstructive coronary arteries; FFR: fractional flow reserve. 
of the data: Ferreira MCMF, Oliveira MV, Paiva MSM, Lemke V, Mangione F, Oliveira GMM. Writing of the manuscript: Ferreira MCMF, Paiva MSM, Lemke V, Mangione F, Oliveira GMM. Critical revision of the manuscript for intellectual content: Ferreira MCMF, Oliveira MV, Oliveira GMM.

\section{Potential Conflict of Interest}

No potential conflict of interest relevant to this article was reported.

\section{References}

1. Schultz WM, Kelli HM, Lisko JC, Varghese T, Shen J, Sandesara P, et al. Socioeconomic Status and Cardiovascular Outcomes: Challenges and Interventions. Circulation 2018; 137(20): 2166-2178.

2. Roth GA, Mensah GA, Johnson CO, Addolorato G, Ammirati E, Baddour LM, et al. Global Burden of Cardiovascular Diseases and Risk Factors, 1990-2019 Update From the GBD 2019 Study. J Am Coll Cardiol. 2020;76(22):2982-3021.

3. Institute for Health Metrics and Evaluation (IHME). GBD Compare I Viz Hub. Disponível em: https://vizhub.healthdata.org/gbd-compare/ (Internet) [Citado em 22 dezembro, 2020]

4. Oliveira GMM, Brant LCC, Polanczyk, CA, Biolo A, Nascimento BR. Malta DC. Estatística Cardiovascular - Brasil 2020. Arq Bras Cardiol. 2020; 115(3):308-439.

5. Brasil. Ministerio da Saúde. DATASUS: Informações de Saúde, Morbidade e Informações Epidemiológicas [Internet]. Brasília: Ministério da Saúde Brasil. 2019 - [cited 2020 feb 3]. Avaible from: http:// datasus.saude.gov.br/informacoes-de-saude/tabnet/epidemiologicas-emorbidade.

6. Mehta LS, Beckie TM, DeVon HA, Grines CL, Krumholz HM, Johnson $\mathrm{MN}$, et al. American Heart Association Cardiovascular Disease in Women and Special Populations Committee of the Council on Clinical Cardiology, Council on Epidemiology and Prevention, Council on Cardiovascular and Stroke Nursing, and Council on Quality of Care and Outcomes Research. Acute Myocardial Infarction in Women: A Scientific Statement From the American Heart Association. Circulation. 2016 Mar 1; 133 (9): 916-47.

7. Kawamoto KR, Davis MB, Duvernoy CS. Acute Coronary Syndromes: Differences between Men and Women. Curr Atheroscler Rep. 2016 Dec; 18 (12): 73.

8. Safdar B, Spatz ES, Dreyer RP, Beltrame JF, Lichtman JH, Spertus JA, et al. Presentation, clinical profile, and prognosis of young patients with myocardial infection with non-obstructive coronary arteries (MINOCA): results from the VIRGO study. J Am Heart Assoc. 2018 Jun 28;7(13):e009174.

9. Pustjens TFS, Appelman Y, Damman P, Ten Berg JM, Jukema JW, de Winter RJ, et al. Guidelines for managing myocardial infarction/injury with non-obstructive coronary arteries (MINOCA): a position paper from the Dutch ACS working group. Neth Heart J. 2020 Mar; 28 (3) 116-130.

10. Hayes SN, Kim ESH, Saw J, Adlam D, Arslanian-Engoren C, Economy KE, et al. American Heart Association Council on Peripheral Vascular Disease; Council on Clinical Cardiology; Council on Cardiovascular and Stroke Nursing; Council on Genomic and Precision Medicine; and Stroke Council. Spontaneous Coronary Artery Dissection: Current State of the Science: A Scientific Statement From the American Heart Association. Circulation. 2018 May 8; 137 (19): e523-e557.

\section{Sources of Funding}

There were no external funding sources for this study.

\section{Study Association}

This study is not associated with any thesis or dissertation work.

\section{Ethics approval and consent to participate}

This article does not contain any studies with human participants or animals performed by any of the authors.

11. Tweet MS, Hayes SN, Pitta SR, Simari RD, Lerman A, Lennon RJ, et al. Clinical features, management, and prognosis of spontaneous coronary artery dissection. Circulation. 2012; 126: 579-588.

12. Malmborg M, Schmiegelow MDS, Nørgaard CH, Munch A, Gerds $\mathrm{T}$, Schou M, et al. Does type 2 diabetes confer higher relative rates of cardiovascular events in women compared with men? Eur Heart J. 2020 Apr 1; 41 (13): 1346-1353.

13. Devon HA, Rosenfeld A, Steffen AD, Daya M. Sensitivity, specificity, and sex differences in symptoms reported on the 13-item acute coronary syndrome checklist. J Am Heart Assoc. 2014; 3 (2): e000586.

14. Lovlien M, Schei B, Gjengedal E. Are there gender differences related to acute myocardial infarction symptoms? Norwegian perspective. Prog Cardiovasc Nurs. 2006 Winter; 21 (1): 14-9.

15. Arora G, Bittner V. Chest pain characteristics and gender in the early diagnosis of acute myocardial infarction. Curr Cardiol Rep. 2015 Feb; 17 (2): 5.

16. Haider A; Bengs S, Luu J, Osto E, Siller-Matula J M, Muka Ta, Gebhard C. Sex and gender in cardiovascular medicine: presentation and outcomes of an acute coronary syndrome. European Heart Journal (2019) 0, 1-14 doi:10.1093/eurheartj/ehz898.

17. Rosano GM, Vitale C, Marazzi G, Volterrani M. Menopause, and cardiovascular disease: the evidence. Climacteric 2007;10(Suppl 1):19-24.

18. Manson JE, Hsia J, Johnson KC, Rossouw JE, Assaf AR, Lasser NL, et al. Estrogen plus progestin and the risk of coronary heart disease. $\mathrm{N}$ Engl J Med 2003; 349:523-534.

19. Muka T, Chowdhury R, Franco OH. Effect of iron levels on women after premature or early-onset menopause-reply. JAMA Cardiol 2017; 2:458-459.

20. Rich-Edwards JW, Fraser A, Lawlor DA, Catov JM. Pregnancy characteristics and women's future cardiovascular health: an underused opportunity to improve women's health? Epidemiol Rev 2014;36:57-70.

21. Grandi SM, Filion KB, Yoon S, Ayele HT, Doyle CM, Hutcheon JA, et al. Cardiovascular disease-related morbidity and mortality in women with a history of pregnancy complications. Circulation, 2019;139:1069-1079.

22. Tanz LJ, Stuart JJ, Williams PL, Rimm EB, Missmer SA, Rexrode KM, Mukamal KJ, Rich-Edwards JW. Preterm delivery and maternal cardiovascular disease in young and middle-aged adult women. Circulation, 2017;135:578-589.

23. Chandiramani R, Mehran R. Sex-Related Differences in Patients at High Bleeding Risk Undergoing Percutaneous Coronary Intervention: A Patient-Level Pooled Analysis From 4 Postapproval Studies. J Am Heart Assoc 2020 Apr 7;9(7): e014611. 
24. Yu J, Mehran R, Grinfeld L, Xu K, Nikolsky E, Brodie B, et al. Sex-based differences in bleeding and long term adverse events after percutaneous coronary intervention for acute myocardial infarction: three-year results from the HORIZONS-AMI trial Catheter. Cardiovasc Interv. 2015 Feb 15;85(3):359-68.

25. Collet JP, Thiele Holger, Barbato E, Barthélémy O, Bauersachs J, L Bhatt D, et al. ESC Scientific Document Group, 2020 ESC Guidelines for the management of acute coronary syndromes in patients presenting without persistent ST-segment elevation: The Task Force for the management of acute coronary syndromes in patients presenting without persistent STsegment elevation of the European Society of Cardiology (ESC), European Heart Journal, ehaa575, https://doi.org/10.1093/eurheartj/ehaa575.

26. Sarma AA, Braunwald E, Cannon CP, Guo J, KyungAh Im, Antman EM, et al. Outcomes of Women Compared With Men After Non-ST-Segment Elevation Acute Coronary Syndromes. J Am Coll Cardiol. 2019 Dec, 74 (24) 3013-3022.

27. Neumann FJ, Sousa-Uva M, Ahlsson A, Alfonso F, Banning AP, Benedetto U, et al. Grupo de Documentos Científicos da ESC, Diretrizes da ESC / EACTS sobre revascularização do miocárdio, European Heart Journal, Volume 40 , Edição 2, 07 de janeiro de 2019, páginas 87-165, https://doi. org/10.1093/eurheartj/ehy394.

28. Redfors $\mathrm{B}$, Angerås $\mathrm{O}$, Råmunddal $\mathrm{T}$, Petursson $\mathrm{P}$, Haraldsson I, Dworeck C, et al. Trends in Gender Differences in Cardiac Care and Outcome After Acute Myocardial Infarction in Western Sweden: A Report From the Swedish Web System for Enhancement of Evidence-Based Care in Heart Disease Evaluated According to Recommended Therapies (SWEDEHEART). J Am Heart Assoc. 2015 Jul 14; 4 (7): e001995.

29. Alabas OA, Gale CP, Hall M, Rutherford MJ, Szummer K, Lawesson SS, Alfredsson J, Lindahl B, Jernberg T. Sex Differences in Treatments, Relative Survival, and Excess Mortality Following Acute Myocardial Infarction: National Cohort Study Using the SWEDEHEART Registry. J Am Heart Assoc. 2017 Dec 14; 6 (12): e007123.

30. Kawamoto KR, Davis, MB, Duvernoy CS. Acute Coronary Syndromes: Differences in Men and Women. Curr Atheroscler Rep. 2016 Dec; 18 (12): 73.

31. Lee KL, Califf RM, Simes J, Van de Werf F, Topol EJ. Holding GUSTO up to the light. Global Utilization of Streptokinase and Tissue Plasminogen Activator for Occluded Coronary Arteries. Ann Intern Med. 1994 May 15; 120 (10): 876-81; discussion 882-5.

32. Slagman A, Searle J, Vollert JO, Storchmann H, Buschenfelde DM, von Recum J, et al. Sex differences of troponin test performance in chest pain patients. Int J Cardiol. 2015; 187: 246-51.

33. Chandiramani R, Cao D, Claessen BE, Sorrentino S, Guedeney P, Blum $\mathrm{M}$, et al. Sex-Related Differences in Patients at High Bleeding Risk Undergoing Percutaneous Coronary Intervention: A Patient-Level Pooled Analysis From 4 Postapproval Studies. J Am Heart Assoc. 2020 Apr 7; 9 (7): e014611.

34. Stefanini GG, Baber U, Windecker S, Morice MC, Sartori S, Leon MB, et al. Safety and efficacy of drug-eluting stents in women: a patient-level pooled analysis of randomized triples. Lancet. 2013; 382: 1878].

35. Ford TJ, Stanley B, Good R, Rocchiccioli P, McEntegart M, Watkins S, et al. Stratified Medical Therapy Using Invasive Coronary Function Testing in Angina: The CorMicA Trial. J Am Coll Cardiol. 2018 Dec 11; 72 (23 Pt A): 2841-2855.

36. Hayes SN, Kim ESH, Saw J, Adlam D, Arslanian-Engoren C, Economy KE, et al; American Heart Association Council on Peripheral Vascular Disease; Council on Clinical Cardiology; Council on Cardiovascular and Stroke Nursing; Council on Genomic and Precision Medicine; and Stroke Council. Spontaneous Coronary Artery Dissection: Current State of the Science: A Scientific Statement From the American Heart Association. Circulation. 2018 May 8; 137 (19): e523-e557.

37. Engstrøm T, Kelbæk H, Helqvist S, Høfsten DE, Kløvgaard L, Holmvang L, et al. DANAMI-3 - PRIMULTI Investigators. Complete revascularization versus treatment of the culprit lesion only in patients with ST-segment elevation myocardial infarction and multivessel disease (DANAMI-3 - PRIMULTI): an open-label, randomized controlled trial. Lancet. 2015 Aug 15; 386 (9994): 665-71.
38. Smits PC, Abdel-Wahab M, Neumann FJ, Boxma-de Klerk BM, Lunde $\mathrm{K}$, Schotborgh CE, et al. Fractional Flow Reserve-Guided Multivessel Angioplasty in Myocardial Infarction. N Engl J Med. 2017 Mar 30; 376 (13): 1234-1244.

39. Mehta SR, Wood DA, Storey RF, Mehran R, Bainey KR, Nguyen H, et al. COMPLETE Trial Steering Committee and Investigators. Complete Revascularization with Multivessel PCI for Myocardial Infarction. N Engl J Med. 2019 Oct 10; 381 (15): 1411-1421.

40. Liou KP, Ooi SM, Hoole SP, West NEJ. Fractional flow reserve in acute coronary syndrome: a meta-analysis and systematic review. Open Heart. 2019 Jan 13; 6 (1): e000934.

41. Kim CH, Koo BK, Dehbi HM, Lee JM, Doh JH, Nam CW, et al. Sex Differences in Instantaneous wave-free Ratio or Fractional Flow ReserveGuided Revascularization Strategy. JACC Cardiovasc Interv. 2019 Oct 28; 12 (20): 2035-2046.

42. Díez-Delhoyo F, Gutiérrez-lbañes E, Sanz-Ruiz R, Vázquez-Álvarez ME González Saldívar H, Rivera Juárez A, et al. Prevalence of Microvascular and Endothelial Dysfunction in the Nonculprit Territory in Patients With Acute Myocardial Infarction. Circ Cardiovasc Interv. 2019 Feb; 12 (2): e007257.

43. Ford TJ, Stanley B, Good R, Rocchiccioli P, McEntegart M, Watkins S Stratified Medical Therapy Using Invasive Coronary Function Testing in Angina: The CorMicA Trial. J Am Coll Cardiol. 2018 Dec 11; 72 (23 Pt A): 2841-2855.

44. Tamis-Holland JE, Jneid H, Reynolds HR, Agewall S, Brilakis ES, Brown $\mathrm{TM}$, et al. American Heart Association Interventional Cardiovascular Care Committee of the Council on Clinical Cardiology; Council on Cardiovascular and Stroke Nursing; Council on Epidemiology and Prevention; and Council on Quality of Care and Outcomes Research. Contemporary Diagnosis and Management of Patients With Myocardial Infarction in the Absence of Obstructive Coronary Artery Disease: A Scientific Statement From the American Heart Association. Circulation. 2019 Apr 30; 139 (18): e891-e908.

45. Lee PY, Alexander KP, Hammill BG, Pasquali SK, Peterson ED Representation of elderly persons and women in published randomized trials of acute coronary syndromes. JAMA 2001; 286:708.

46. Kim ES, Carrigan TP, Menon V. Enrollment of women in National Heart, Lung, and Blood Institute-funded cardiovascular randomized controlled trials fails to meet current federal mandates for inclusion. J Am Coll Cardiol 2008; 52:672.

47. O'Donoghue M, Boden WE, Braunwald E, Cannon CP, Clayton TC, Winter RJ, et al. Early invasive vs conservative treatment strategies in women and men with unstable angina and non-ST-segment elevation myocardial infarction: a meta-analysis. JAMA 2008; 300:71.

48. DeFilippis EM, Collins BL, Singh A, Biery DW, Fatima A, Qamar A, et al. Women who experience a myocardial infarction at a young age have worse outcomes compared with men: the Mass General Brigham YOUNG-MI registry. Eur Heart J 2020; 41:4127.

49. Antoniucci D, Valenti R, Moschi G, Migliorini A, Trapani M, Santoro GM, Bolognese, Dovellini EV, et al. Sex-based differences in clinical and angiographic outcomes after primary angioplasty or stenting for acute myocardial infarction. Am J Cardiol 2001; 87:289.

50. Stone GW, Grines CL, Browne KF, Marco J, Rothbaum D, O'Keefe J, et al. Comparison of in-hospital outcome in men versus women treated by either thrombolytic therapy or primary coronary angioplasty for acute myocardial infarction. Am J Cardiol 1995; 75:987.

51. Sullivan AK, Holdright DR, Wright CA, Sparrow JL, Cunningham D, Fox KM, et al. Chest pain in women: clinical, investigative, and prognostic features. BMJ 1994; 308:883.

52. Gurevitz O, Jonas M, Boyko V, Rabinowitz B, Reicher-Reiss H. Clinical profile and long-term prognosis of women $<$ or $=50$ years of age referred for coronary angiography for evaluation of chest pain. Am J Cardiol 2000; 85:806.

53. Buchthal SD, den Hollander JA, Bairey Merz CN, Rogers WJ, Pepine CJ, Reichek N, et al. Abnormal myocardial phosphorus-31 nuclear magnetic resonance spectroscopy in women with chest pain but normal coronary angiograms. N Engl J Med 2000; 342:829. 
54. Johnson BD, Shaw LJ, Buchthal SD, Merz Bairey CN, Kim HW , Scott $\mathrm{KN}$, et al. Prognosis in women with myocardial ischemia in the absence of obstructive coronary disease: results from the National Institutes of Health-National Heart, Lung, and Blood Institute-Sponsored Women's Ischemia Syndrome Evaluation (WISE). Circulation 2004; 109:2993.

55. Mehta LS, Beckie TM, DeVon HA, Grines CL, Krumholz HM, Johnson MN et al. Acute Myocardial Infarction in Women: A Scientific Statement from the American Heart Association. Circulation. 2016 Mar 1;133(9):916-
47 3- Thygesen K, et al. Fourth Universal Definition of Myocardial Infarction (2018). Circulation. 2018 Nov 13;138(20):e618-e651.

56. Mauvais-Jarvis F, Merz NB, Barnes PJ, Brinton RD, Carrero JJ, DeMeo $\mathrm{DL}$, et al. sex and gender: modifiers of health, disease, and medicine. Lancet 2020; 396: 565-82

57. Greenwood BN, Carnahan S, Huang L. Patient-physician gender concordance and increased mortality among female heart attack patients. Proc Natl Acad Sci USA 2018; 115: 8569-74. 